\title{
Research on Dust Suppression Technology of Shotcrete Based on New Spray Equipment and Process Optimization
}

\author{
Pengcheng Li, ${ }^{1}$ Zhi Zhou, ${ }^{1}$ Lianjun Chen $\mathbb{D}^{1,2,3}$ Guoming Liu ${ }^{1},{ }^{1}$ and Wei Xiao' \\ ${ }^{1}$ College of Mining and Safety Engineering, Shandong University of Science and Technology, Qingdao 266590, China \\ ${ }^{2}$ State Key Laboratory of Mining Disaster Prevention and Control, \\ Shandong Province and the Ministry of Science and Technology, Shandong University of Science and Technology, \\ Qingdao 266590, China \\ ${ }^{3}$ National Demonstration Center for Experimental Mining Engineering Education, \\ Shandong University of Science and Technology, Qingdao 266590, China
}

Correspondence should be addressed to Guoming Liu; lgmrenqing@163.com

Received 23 October 2018; Accepted 3 February 2019; Published 3 March 2019

Academic Editor: Qingliang Yu

Copyright ( 12019 Pengcheng Li et al. This is an open access article distributed under the Creative Commons Attribution License, which permits unrestricted use, distribution, and reproduction in any medium, provided the original work is properly cited.

In order to reduce the dust hazard of shotcrete, the paper analyzed the mechanism of dust production from the perspective of various dust sources and developed the plunger-type wet spraying machinery and wet mixer which can be applied in the smallsection tunnel for reducing dust on the root cause. The dust concentration between dry-mix shotcrete and wet-mix shotcrete was compared and analyzed. The results showed that the average total dust concentration and respirable dust concentration in the process of dry spraying were $99.4 \mathrm{mg} / \mathrm{m}^{3}$ and $52 \mathrm{mg} / \mathrm{m}^{3}$, respectively, while $9.8 \mathrm{mg} / \mathrm{m}^{3}$ and $4.08 \mathrm{mg} / \mathrm{m}^{3}$ in the wet-mix shotcrete process, and the average dust concentration decreased by more than $90 \%$ after applying new wet-mix shotcrete outfits. The clean zone of dust was divided according to the dust distribution. Finally, the dust suppression technology was optimized by using an accelerator and adjusting wind pressure and spraying angle. Results indicated that the application of the accelerator reduced the dust production efficiently; moreover, when the wind pressure was $0.2 \mathrm{MPa}$ with $1 \mathrm{~m}$ spraying distance and $90^{\circ}$ angle of spraying, the dust concentration and rebound reached the minimum.

\section{Introduction}

Nowadays, the prediction and prevention technology of underground natural disasters is becoming more mature [1-8]. In the case of anchor shotcrete support [9], the drymix shotcrete or semiwet shotcrete are still prevalent in anchoring and shotcreting in China. Although these technologies are simple, dust concentration in the anchoring and shotcreting working face was very high [10]. The total and respirable dust concentrations in some working areas of guniting under the poor condition were up to more than $500 \mathrm{mg} / \mathrm{m}^{3}$ and $150 \mathrm{mg} / \mathrm{m}^{3}$, respectively $[11,12]$. The high level of silicon dioxide in dust leads to silicosis easily and was harmful to the physical and psychological health of workers. In 2013, a total number of 26,000 occupational diseases were reported, including 23,000 dust phthisis which accounted for $85 \%$ of the total reported occupational diseases in China
[13]. By the end of 2015, the dust phthisis is still serious in reported occupational diseases [14]. As for a tunnel or mine roadway in China, the number of people exposed to dust is the largest in the world and the condition of dust in the process of anchoring and shotcreting is the worst, as is shown in Figure $1[15,16]$.

Therefore, it is urgent to weed out the traditional drymix shotcrete technology and develop the technology of dust suppression. Therein, the wet-mix shotcrete technology should be promoted for applying in a tunnel or roadway. No matter from the perspective of enterprise safety or health of workers, the application of wet-mix shotcrete technology for reducing dust concentration in the working face is of utmost significance to improve the spraying quality and efficiency [17].

Zeng and Zhou $[18,19]$ researched the magnetized water mixed in shotcrete for reducing the dust density and reported 


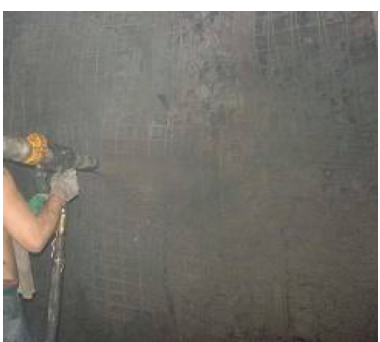

(a)

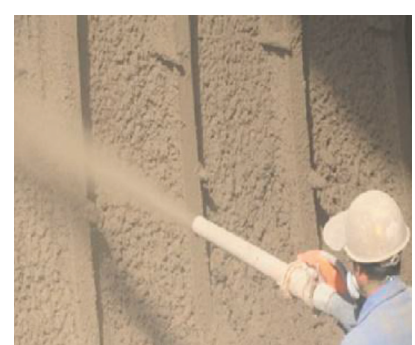

(b)
FIgURE 1: Dust production in shotcreting site. (a) Coal mine roadway. (b) Tunnel.

that it could reduce the dust density by $50 \%$ in comparison with the ordinary shotcrete. Zhou et al. [11,20] developed a new type of alkali-free liquid accelerator for wet-mix shotcrete in order to address issues such as high dust concentration and large rebound rate. Bakke et al. [21] identified determinant of dust exposure containing shotcrete in tunnel construction work and proposed the control measures with special ventilated, closed cabs. In addition, the methods of numerically simulating, dust-suppressant development and high-pressure water injection to study the dust removing technology in the fully mechanized mining face and the fully mechanized workface are worth learning [22-28].

However, these scholars above did not study the shotcreting process for reducing dust by adjusting shotcreting parameters. In addition, the same wet-mix shotcrete equipment has been developed at home and abroad, but these machines commonly have big volume that is difficult for application in a narrow section tunnel $[29,30]$.

Hence, aiming at the working area of China's tunnel or roadway that are generally narrow and small with complicated environment, especially in mine roadway, the paper analyzed the mechanism of dust production from the view of multiple dust sources and developed the new wetmix shotcrete equipment with small volume based on the mechanism of dust production, and finally, the dust suppression technology was optimized by adjusting spraying parameters and adding admixtures.

\section{Mechanism of Dust Production in Shotcreting Process}

According to the onsite experience and reports of shotcrete, the dust was mainly produced in the two processes of spraying and loading $[29,31]$.

2.1. Dust Produced in Spraying. When the mixture is sprayed from the nozzle by high-pressure gas, the isolation of concrete stream and the resilience of surface sprayed under the action of high-pressure air lead to the separation and irradiation of dust, causing the rapid increase of dust generated between nozzle and spray surface. The dust produced under such condition is the maximum, accounting for over $80 \%$ of the total quantity [32]. The reasons of dust production are almost as follows.
2.1.1. Dust Produced by the Diffusion Effect of Spraying Airflow with High Speed. Concrete stream in the spray gun is a confined space jet whose wall restricts the spraying. When high-pressure air blows materials from a spraying nozzle in the state of turbulent flow, because suppressed air pressure declines suddenly and its volume expands violently after the nozzle, part of powdery mixture spreads so quickly that dust concentration of working face increases. After materials are blown out, flow field gets larger and velocity decreases suddenly. And, the material-carrying capability of the air stream declines accordingly. As wind pressure gets larger, decreased magnitude of spraying concrete pressure at the nozzle gets larger so that micrograins produced become more. Field observation shows that, in dry-mix shotcrete equipment, dry cement amount of the concrete near the nozzle is up to between $20 \%$ and $25 \%$ [33]. According to present dry-mix shotcrete techniques, the phenomenon that dry powdery mixture occurs in concrete stream is inevitable [34].

2.1.2. Dust Produced by Shear and Collision of High-Speed Spraying Airflow. As the spraying stream mixes with relative static air in the shotcreting process, the exchange of quality and momentum occurs. Hence, the original static air is entrained into jet flow, being driven forward forming discontinuous interface and vortex into turbulence. The spraying nozzle with circular movement or axial repeated movement when shotcreting in the process of bolt-shotcrete forms a kind of swirling jet with complex flow. The field of shear flow can promote particles to strengthen gas phase turbulent immensely. High-speed shear stream produced by jetting can destroy concrete aggregate clusters. And, collision among aggregates and collision between aggregates and wall can break cluster renewal. After aggregates fracture, dust and materials are blown by the wind, causing the production and proliferation of spraying dust [35].

2.2. Production of Dust in Loading Process. The moving dust particles are subjected to various forces, such as mechanical force, gravity, and the force of Brownian motion and air flow in the general conditions, among which airflow force has the greatest influence on the diffusion of dust $[36,37]$. In the loading process, when materials fall whose velocity increases with the law of free falling body, the main force is pulverization action of shear and compressed airflow.

Due to the relative movement among them, materials are in dislocation and the original stacking structures are destroyed. Stirring materials fall irregularly and discontinuously. In the movement process, air is subjected to the impact force of frontal surface and the friction of material particles, producing vortex. So, the air pressure of particles on the posterior and sides declines. Surrounding air is dragged into the surface of material layers and material flow and then into the feed inlet with materials, inducing the airflow to promote proliferation of dust particles.

When materials fall on the entrance, the porosity of the material varies because materials ted, soar, and leap discontinuously. Moreover, they will regain the original 
stacking state until contacting the rigid plane, and at the same time, air is violently extruded from material intervals. With ultrafine dust overflowing, the upward shear airflow appears around, causing harmful dust flow [38]. Aimed at the reason of dust production, the internal cause is undermixing of spraying materials and low viscidity while the external cause is the collision among granules and the crash against a roadway wall. As for wet-mix shotcrete, due to strong stirring viscosity, dust produced is smaller than dry-mix shotcrete prominently in the spraying process.

\section{Development of New Wet-Mix Shotcrete Equipment}

Wet-mix shotcrete can reduce dust in the process of mixing and spraying. The literatures [39] shows that the wet-mix shotcrete only produces less dust in the nozzle and the dust source in the other working processes (except artificially loading material) is basically eliminated when compared with dry-mix shotcrete. Therefore, the fundamental way to solve the serious dust problem is to develop and promote the wet-mix shotcrete equipment.

Combining with the mechanism of dust production, wet-mixing materials is the basis for reducing the dust produced by spraying and loading materials because wet material clusters, owning better viscosity that can capture dust, are hardly diffused by the shear of high-speed velocity, which is beneficial for the dust suppression. However, the existing wet-mix shotcrete equipment with big volume is difficult to apply in a small-section roadway or tunnel, preventing the promotion and application of wetmix shotcrete. In order to solve this problem, cooperating with enterprises and Wit laboratory Mine Equipment Co., Ltd, Robot Research Center in Shandong University of Science and Technology in China, regarding the dust suppression target as the center, the new wet-mix shotcrete equipment was developed for small-section tunnel or roadway, including mixing system and pumping system.

3.1. Development of Wet Mixing and Feeding Machines. The wet mixing and feeding machines were developed, called MJDY-250T-type mixer, which adopts single horizontal shaft forced mixing, hydraulic drive, and the way of turning out material. It can achieve the sufficient mixing of water and materials, improving the viscosity of fresh concrete to reduce the dust escape when the mass of the material is in the process of transport and spraying. The mixing device uses wheeled mobile chassis, the wheel is installed under the machine frame (the wheel distance is 600 or $900 \mathrm{~mm}$ ), and it can also be dragged or transported by the flat car. The main parts of the wet mixing and deeding machines (mixer) are shown in Figure 2, and the main technical parameters are displayed in Table 1. For displaying the inner structure clearly, the feed mechanism was drawn at negative direction in the schematic diagram.

3.2. Development of Wet Spraying Machine. Wet-mix shotcrete machine adopts the double piston pumps, which is
SPB7-T plunger-type wet spraying machinery. When the fresh concrete is entrained into a pumping cylinder, the concrete is pushed by a powerful hydraulic power from the other pumping cylinder, passing the S-pipe valve to the delivery pipeline. The stroke rate of the pumping cylinder can be adjusted manually by the handle on the hydraulic pump. The $S$ valve is switched by using two hydraulic pistons with a swing cylinder. The mobile chassis with rubber or rail wheels is used. Shotcrete prepared is poured into the hopper that is treated as a filler auxiliary device of the concrete transfer pump and a storage device. The height of the hopper is in conformity with the height of the mixer, and the width of the machine is less than $1 \mathrm{~m}$. The machine can be applied in the small-section roadway underground, walking flexibly and conveniently. It can also reduce the movement number of wet-mix shotcrete machines and achieve long-distance shotcrete in an extremely narrow space. The main parts of wet-mix shotcrete machine are shown in Figure 3, and its main technical parameters are displayed in Table 2.

\section{Experimental Materials and Program}

\subsection{Materials and Mix Proportions}

4.1.1. Cement and Aggregates. Two kinds of shotcrete, wet and dry, were studied in this work, and its mix proportions are given in Table 3. The cement was Portland cement (Type I) with a density of $3150 \mathrm{~kg} / \mathrm{m}^{3}$. The sand was a natural river sand with a specific gravity of 2.57 and fineness modulus of 2.65. For coarse aggregates, it was a crushed rock with a maximum size of $10 \mathrm{~mm}$, specific gravity of 2.65 , and fineness modulus of 5.70. The gradation curves for both coarse and fine aggregates used meet the National Standards C25 of GB50086-2001 (Specifications for Bolt-Shotcrete Support). The amount of water mixed in concrete was corrected to take into account the water absorbed by aggregates.

4.1.2. Chemical Admixture. A polycarboxylate-based water reducing admixture (Type PCA, purchased from ShaxiQinfen Building Materials Co., Ltd) was used. And, two kinds of accelerators (WT-N1 and HYAC, purchased from Wit Laboratory Mine Equipment Co., LTD and Laiyang macro auspicious building admixture Co., LTD, respectively) were also used. The physical properties of each chemical admixture employed are displayed in Tables 4-6, respectively.

The dosages of the admixture varied as required that can generate a slump of $110 \pm 20 \mathrm{~mm}$ for wet-mix shotcrete, marked as \%, meaning the percentage of the admixture relative to the binder content (in mass). In the process of dry-mix shotcrete, sand and coarse aggregates were mixed for $25 \mathrm{~s}$ and cement was added during $15 \mathrm{~s}$; then, the mixing materials were transported by pressure air across a delivery hose, and water was added at the nozzle. The mixing procedure of wet-mix shotcrete was as follows: sand and coarse aggregates were mixed for $20 \mathrm{~s}$, cement was added during $15 \mathrm{~s}$, and water and water-reducing admixture were then added during an additional two minutes of mixing. The accelerator was injected with compressed air at the spray 


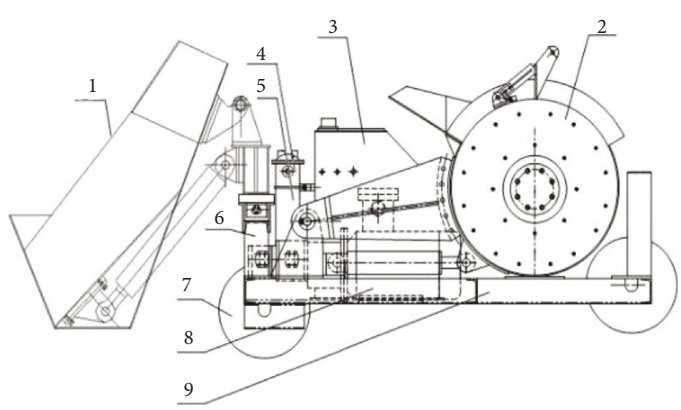

(a)

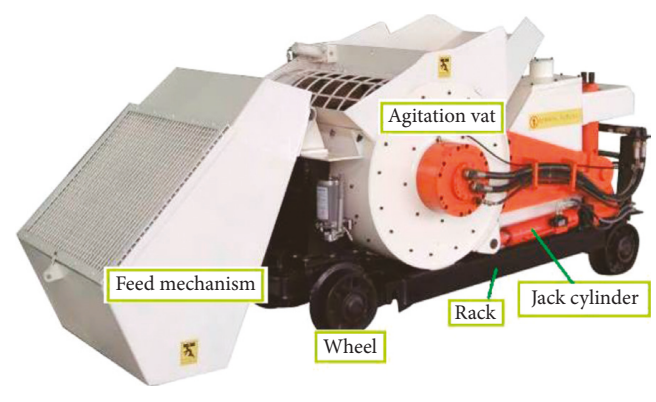

(b)

FIGURE 2: Schematic diagram of main components of the new wet mixing and feeding machines (mixer) and their real product photo. 1: feed mechanism with single cylinder; 2: agitation vat; 3: hydraulic oil tank; 4: cooling unit; 5: operating handle; 6: duplex gear pump; 7: wheel; 8: jack cylinder; 9: rack.

TABLE 1: Main technical parameters of the mixer.

\begin{tabular}{lc}
\hline Basic parameters & Value \\
\hline Motor power & $18.5 \mathrm{KW}(660 / 1140 \mathrm{~V})$ \\
Hydraulic system pressure & $16 \mathrm{MPa}$ \\
Speed of main shaft & $20 \mathrm{r} / \mathrm{min}$ \\
Stir well time & $\leq 60 \mathrm{~s}$ \\
Bucket capacity & $500 \mathrm{~L}$ \\
Charging capacity & $400 \mathrm{~L}$ \\
Loading height & $550 \mathrm{~mm}$ \\
Discharge height & $1300 \mathrm{~mm}$ \\
Length $\times$ width $\times$ height & $3500 \mathrm{~mm} \times 1300 \times 1400$ \\
Weight & $2326 \mathrm{~kg}$ \\
\hline
\end{tabular}

gun. For the mixtures after shotcreting, the compressive strength varied between 27.9 (DS1) and 38.3 $\mathrm{MPa}$ (WA0).

4.2. Shotcrete System. The experiments in this paper were conducted in the underground roadway with length, width, and height of $300 \mathrm{~m}, 5.5 \mathrm{~m}$, and $5 \mathrm{~m}$, respectively, at Tangkou coal mine. The rotor-type spray machine for dry-mix shotcrete was employed. The wet-mix equipment with a double-plug pump was applied. The length of pipeline can be changed by adding or removing some sections of steel pipes or hose. The wet-mix shotcrete system was used to determine the relationship between the spraying parameters and the spraying efficiency such as dust concentration and rebound rate. Details of the test can be found in Chen's reports [40].

4.3. Dust and Rebound Measurement. The filter weighing method was used for dust measurement. The dust measurement was conducted when shotcrete operation reached up to a stable condition. The measurement points were listed in Figure 4. In the process of rebound measurement, a plastic film was laying on the bottom slab of the roadway. Next, a certain quantity of concrete was sprayed onto the walls and arch of the roadway, and the rebound material was collected, weighted, and calculated after spraying. The average value of the rebound rate from walls and arch was treated as the final rebound rate of each mixture. The experiments followed the standard GB50086-2001.

\section{Shotcreting Dust Measurement and Clean Zone Division}

5.1. Dust Comparison of Dry-Mix and Wet-Mix Shotcrete. Figure 5 shows the dust concentration comparison between dry-mix shotcrete (DS1) and wet-mix shotcrete (WA0). In the semiclosed roadway, DS1 produced more dust than WA0, seriously polluting the ambient environment. In terms of DS1, the sequence of total or respirable dust concentration was $3 \#>1 \#>2 \#>4 \#>5 \#$. The highest concentration value appeared at $3 \#$ point in DS1 near the loading and mixing area, along with total dust concentration $169 \mathrm{mg} / \mathrm{m}^{3}$ and respiratory dust concentration $86 \mathrm{mg} / \mathrm{m}^{3}$. The second area with high dust concentration was at 1 \# point near the drymix shotcreting workface, and the total and respirable dust concentrations were up to $95.5 \mathrm{mg} / \mathrm{m}^{3}$ and $49 \mathrm{mg} / \mathrm{m}^{3}$, respectively. These two points, $3 \#$ and $1 \#$, are the important areas where operation staff often stay, with corresponding dust concentration enormously exceeding the limit required by the National Standard for industrial place. According to some reports [41], adopting the combination way with mist spray and dust removal fan could effectively reduce shotcrete dust with $90 \%$ dust removal rate; however, too much mist spray led to the damp work face and wet work cloths, vastly affecting shotcrete operation.

In terms of WA0, the whole operation was obviously clean with low dust concentration in Figure 5. The highest dust value was at $1 \#$ near the spraying area with total dust concentration $14.8 \mathrm{mg} / \mathrm{m}^{3}$ and respirable dust concentration $5.3 \mathrm{mg} / \mathrm{m}^{3}$, reduced by about $80 \%$ when compared with DS1. At the mixing area, dust concentration was decreased by more than $90 \%$. In a whole, wet-mix shotcrete could efficiently improve the shotcrete operation environment and protect the workers in the underground shotcrete support. It is noted that the reason why DS1 produced much dust attributed to the dry-mix shotcrete spray machine and the management style in the underground roadway is not ignored.

5.2. Clean Zone Division of Wet-Mix Shotcrete. The wet-mix shotcrete technology has reduced dust in the working face greatly. But, some residual dust in some special areas may 


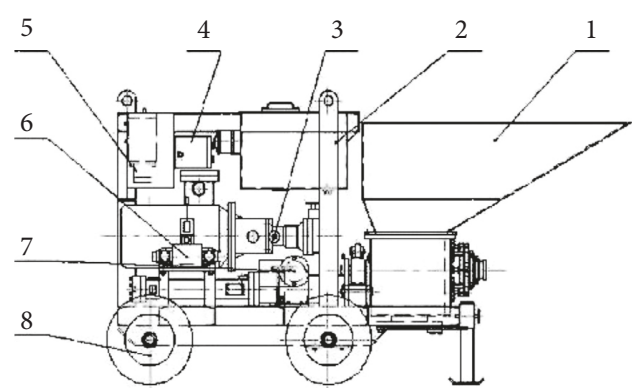

(a)

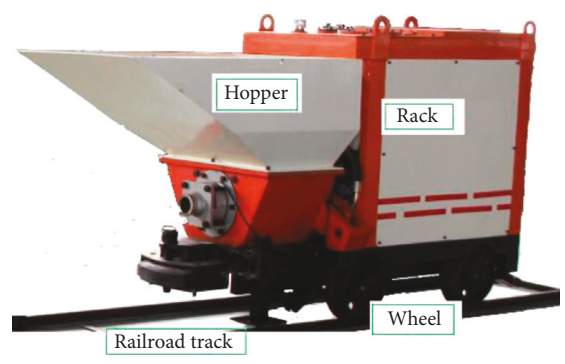

(b)

FIGURE 3: Schematic diagram of main components of new wet spraying machine and its real product photo. 1: hopper; 2: rack; 3: oil hydraulic pump; 4: cooling system; 5: lubrication system; 6: operating handle; 7: pumping system; 8: wheel.

TABle 2: Main technical parameters of new wet-mix shotcrete machine.

\begin{tabular}{lc}
\hline Basic parameters & Value \\
\hline Mains input & $660 \mathrm{~V} / 1140 \mathrm{~V}$ \\
Motor power & $18.5 \mathrm{~kW}$ \\
Maximal system pressure & $21 \mathrm{MPa}$ \\
Nominal working pressure & $16 \mathrm{MPa}$ \\
Hopper capacity & $300 \mathrm{~L}$ \\
Production capacity (theoretical value) & $7 \mathrm{~m}^{3} / \mathrm{h}$ \\
Transmission distance (H/V) & $300 \mathrm{~m} / 50 \mathrm{~m}$ \\
Working air pressure & $0.4-0.6 \mathrm{Mpa}$ \\
Air consumption & About $10 \mathrm{~m}^{3} / \mathrm{min}$ \\
Weight & $1300 \mathrm{~kg}$ \\
Length $\times$ width $\times$ height & $3200 \times 980 \times 1300 \mathrm{~mm}$ \\
\hline
\end{tabular}

threaten the health of workers, even damage the precision instruments used in the tunnel. Hence, according to the law of dust distribution in the work area of wet-mix shotcrete, the relative clean zone can be divided by the methods proposed by Chen et al. [40].

Figure 6 shows the dust distribution during wet-mix shotcrete. The theory of "three dust zones" was proposed according to these experiments with about $10-20 \mathrm{~m}$ conveying distance. The operating space of wet-mix shotcrete was divided into three zones: "dust early warning area," "clean zone," and "dust warning area". The area with larger dust concentration was called as "dust warning area" between the spraying gun and the downwind side $5-10 \mathrm{~m}$ of shotcrete machines. For necessary workers, the protective measures are needed. For other personnel, they are forbidden to enter into the area. Moreover, an eye-catching warning signs should be placed near this area.

The dust was diffused throughout the whole section under the action of the wind. Along the downwind side, some dust was captured by rock or fell under the action of gravity, leading to the sharp decrease in dust concentration. The area at the downwind side $10-20 \mathrm{~m}$ of the mixer was defined as "dust early warning area" with low dust concentration. The area after "dust early warning area" was treated as "clean area." It was suggested that except the wetmix shotcrete staff, other staff should be in the "clean zone" in order to protect workers, as shown in Figure 6. The dust zone division was ever reported in literature [41], but that was limited in the delivery distance, and the mixing area with high dust concentration was ignored.

Therefore, in order to obtain the precise zone divided, we still followed the methods of Chen et al. [40], and corresponding layout of measurement points is listed in Figure 7. The experiments using the mix proportion of WC0 were conducted with $100 \mathrm{~m}$ long-distance pipeline delivery. According to the dataset in Table 7, we concluded that the clean area can be adjusted with additional experiments. In brief, when regarding the mixing machines as a divided center, "dust warning area" was defined within $0-5 \mathrm{~m}$ radius approximately, "early warning area" is about in $5-15 \mathrm{~m}$ radius, and other areas are "clean zone"; when regarding the spray gun as a divided center, "dust warning area" was defined within about $0-10 \mathrm{~m}$ radius, "early warning area" is about in 10-20 m radius, and other areas were "clean zone", as shown in Figure 8.

\section{Optimization of Dust Suppression Technology of Wet-Mix Shotcrete}

In terms of construction technology, after the mixture ratio and aggregate gradation are determined, the effect of wetmix shotcrete is just restricted by other factors such as the spraying angle, velocity, distance, and the application of additives. Therefore, the process of wet-mix shotcrete was studied to get the best spraying efficiency with $10-20 \mathrm{~m}$ delivery distance. Note that measurements below about dust adopted the layout of the shotcrete system in Figure 4.

6.1. Application of Accelerator. Literature studies [11, 18, 42] reported that the application of accelerator can reduce dust and rebound because of the function of advancing setting. Two kinds of accelerators were selected and tested for reducing dust concentration. Only two points of $1 \#$ and 3\# were tested, owing to the relatively high dust concentration (total dust) proposed above in Section 4.2. The results tested are shown in Figure 9.

It can be seen in Figure 9 that all the dust concentrations are less than $10 \mathrm{mg} / \mathrm{m}^{3}$ in the process of wet-mixing shotcrete with the accelerator. It shows that adding the accelerator can reduce the dust concentration efficiently, further improving the environment quality of the wet-mix 
TABLE 3: The mixture proportions of shotcrete.

\begin{tabular}{lccccccc}
\hline Mixture ID & Type & Water $\left(\mathrm{kg} / \mathrm{m}^{3}\right)$ & Cement $\left(\mathrm{kg} / \mathrm{m}^{3}\right)$ & Sand $\left(\mathrm{kg} / \mathrm{m}^{3}\right)$ & Coarse aggregate $\left(\mathrm{kg} / \mathrm{m}^{3}\right)$ & PCA (\%) & Accelerator $(\%)$ \\
\hline DS1 & Dry & 210 & 430 & 887 & 723 & - & - \\
WA0 & & 183 & 432 & 992 & 643 & 0.40 & - \\
WA1 & Wet & 200 & 424 & 985 & 641 & 6.36 \\
WA2 & & 172 & 440 & 997 & 641 & 6 WT-N1 \\
\hline
\end{tabular}

TABle 4: Physical properties of the PCA-type water-reducing admixture.

\begin{tabular}{lcccc}
\hline Appearance & Active component & Solid-containing content (\%) & Water-reducing rate (\%) & Mixing amount (\%) \\
\hline Clear liquid & Polycarboxylate & 40 & $>35$ & $0.3-0.5$ \\
\hline
\end{tabular}

TABLE 5: Physical properties of the WT-N1-type nonalkali liquid accelerator.

\begin{tabular}{lccccc}
\hline Appearance & $\begin{array}{c}\text { Initial setting } \\
\text { time }(\mathrm{min})\end{array}$ & $\begin{array}{c}\text { Final setting } \\
\text { time }(\mathrm{min})\end{array}$ & $\begin{array}{c}\text { Solid-containing } \\
\text { content }(\%)\end{array}$ & Active component & Mixing amount (\%) \\
\hline Brownish liquid & $2-3$ & $7-9$ & 61.4 & Aluminum sulfate & $4-8$ \\
\hline
\end{tabular}

TABle 6: Physical properties of the HYAC-type accelerator.

\begin{tabular}{lccccc}
\hline Appearance & Initial setting time $(\mathrm{min})$ & Final setting time $(\mathrm{min})$ & Fineness & Active component & Mixing amount $(\%)$ \\
\hline Brownish powder & $2-3$ & $8-10$ & 12.6 & Aluminum oxygen chamotte & $3-10$ \\
\hline
\end{tabular}

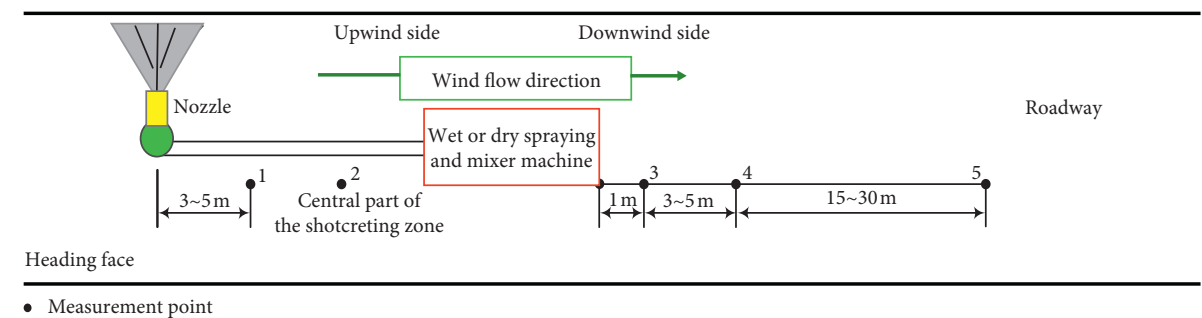

- Measurement point

FIGURE 4: The layout of shotcrete system and the sampling points for measuring the dust.

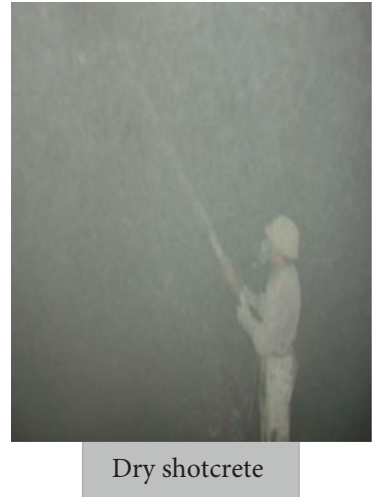

(a)

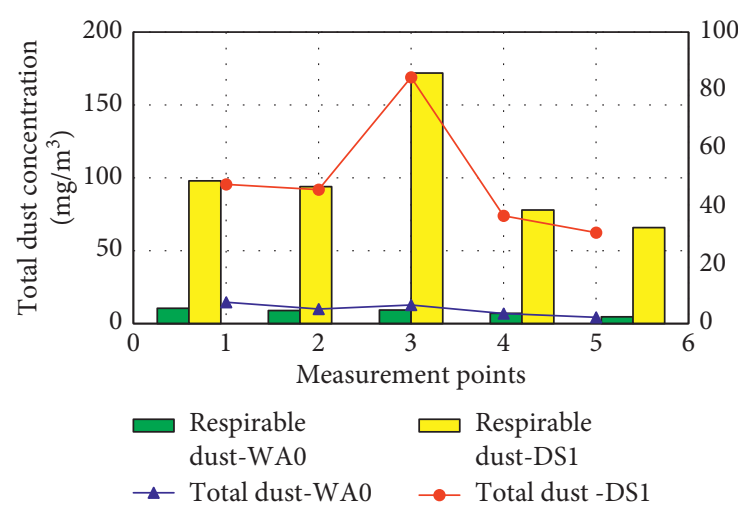

(b)

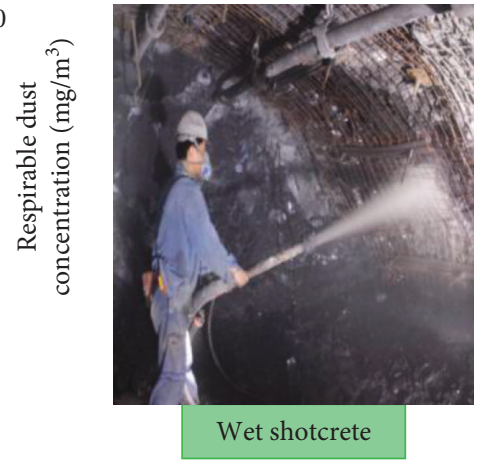

(c)

FIGURE 5: Dust comparison of working site between dry-mix and wet-mix shotcrete.

shotcreting field. Compared with the experiments without adding the accelerator, the application of the accelerator has achieved a better effect on dust suppression because the accelerator can promote the rapid condensation of cement, through the chemical reaction with the cement, resulting in the dust particles being early captured and quickly condensed.

At 3 \# point, the dust concentration of WA1 and WA2 was all reduced because the dust superposed, being blew from the spray gun, was declined after using the accelerate in 


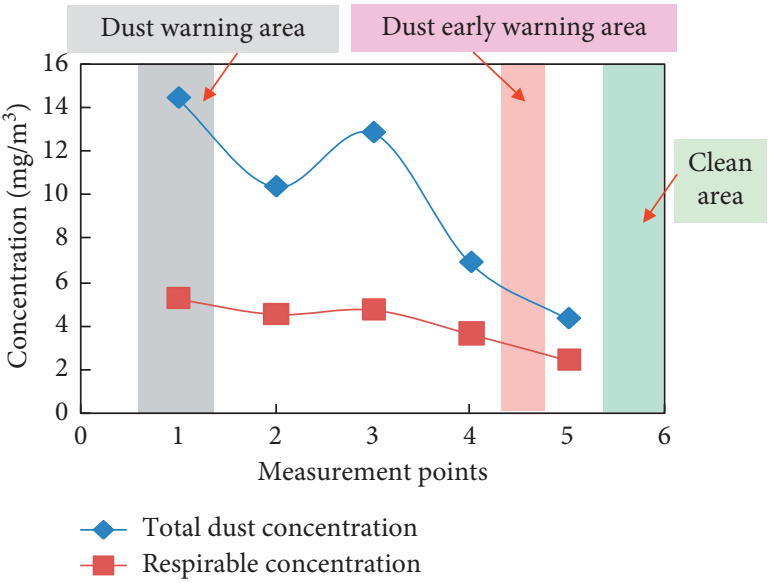

FIgURE 6: Dust concentration distribution of wet-mix shotcrete (WC0).

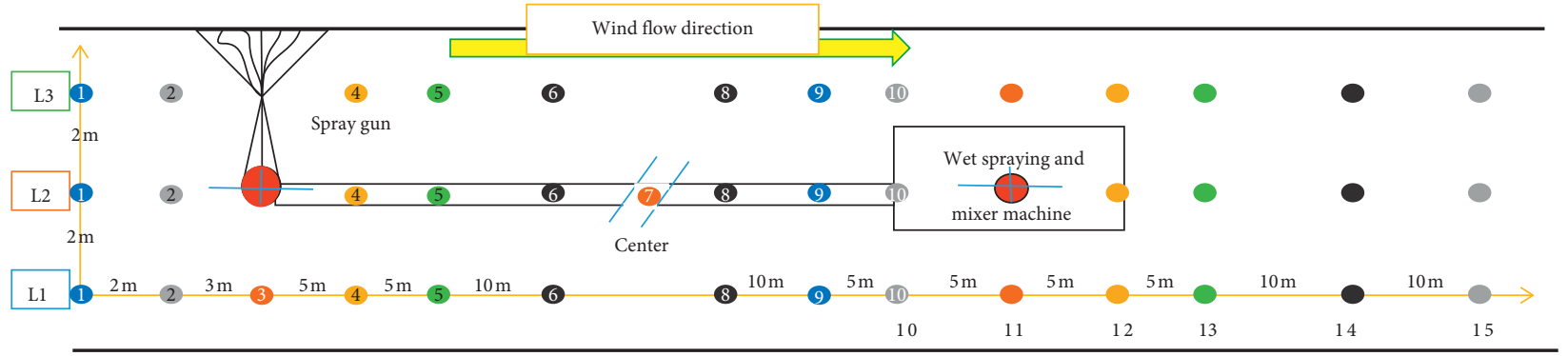

FIGURE 7: New measurement points in the long-distance pipeline.

TABLE 7: Total dust concentration at various measurement points $\left(\mathrm{mg} / \mathrm{m}^{3}\right)$.

\begin{tabular}{|c|c|c|c|c|c|c|c|c|c|c|c|c|c|c|c|}
\hline No. & 1 & 2 & 3 & 4 & 5 & 6 & 7 & 8 & 9 & 10 & 11 & 12 & 13 & 14 & 15 \\
\hline L3 & 2.1 & 9.5 & - & 15.8 & 10.4 & 3.6 & - & 1.5 & 4.2 & 10.2 & 13.1 & 11.7 & 7.4 & 3.4 & 1.1 \\
\hline $\mathrm{L} 2$ & 1.4 & 8.7 & - & 14.6 & 9.3 & 4.7 & 1.1 & 0.8 & 3.5 & 10.6 & - & 12.5 & 6.2 & 4.2 & 0.8 \\
\hline L1 & 0.9 & 6.8 & 14.2 & 13.1 & 7.2 & 3.2 & - & 0.4 & 2.7 & 11.3 & 11.7 & 12.2 & 5.7 & 2.4 & 0.6 \\
\hline
\end{tabular}

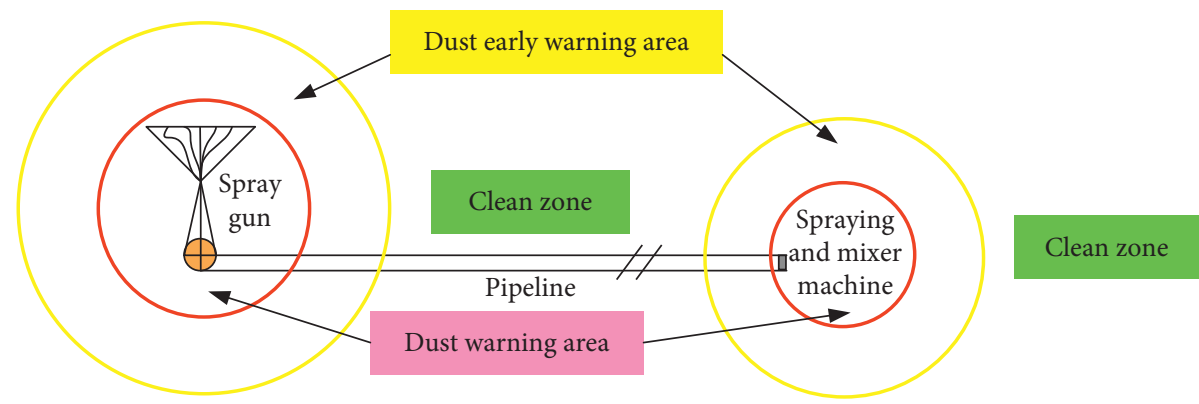

FIgURE 8: Schematic diagram of dust zone divided for long-distance pipage.

the short distance delivery. The powder accelerator of WA2 presented a better effect on the whole shotcreting field. However, the powder accelerator, owning relatively high alkalinity, may be harmful for workers health and cause additional strength loss, so it should be used prudently. According to the comprehensive comparison, the dust concentration after the application of accelerator was reduced by about $55 \%$.
6.2. Spraying Velocity and Wind Pressure. The spraying velocity of concrete stream, related to the wind pressure added at the exit of spraying nozzle, is an important condition to ensure the concrete to obtain a larger density and compaction effect. Therefore, the spraying pressure is also a necessary parameter in the process of shotcrete, which has a great influence on the dust concentration and rebound rate $[43,44]$. By adjusting the wind pressure until the best impact 


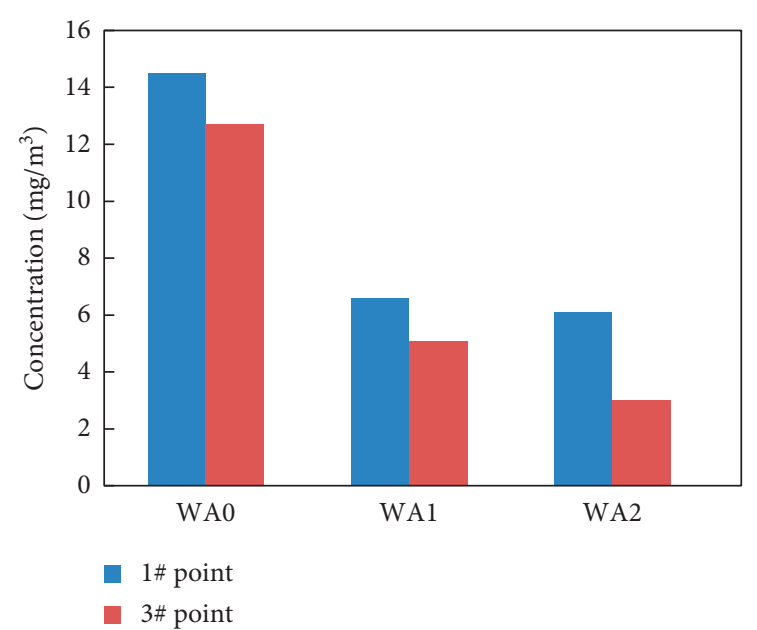

Figure 9: Total dust concentration of $1 \#$ and 3\# points.

value is obtained in the work, the concrete slurry is placed against the sprayed wall and a compact shotcrete layer is formed. Hence, it is important for shotcrete to select optimal spraying wind pressure that can guarantee the better compaction of concrete layer and not cause larger dust and rebound.

In order to determine the optimal spraying wind pressure, the dust concentration and rebound rate were selected as the judgment standard of the spraying parameters that were convenient and quick for measuring. The spraying distance away from the wall sprayed was $1 \mathrm{~m}$ in the tests, which was commonly used for manual shotcrete [45]. The materials of WA1 were used, and 1\# point was measured.

Figure 10 shows that both dust concentration and rebound rate all firstly declined and increased with the wind pressure increasing. When wind pressure was about $0.2 \mathrm{MPa}$, the shotcreting efficiency was best including minimum total dust concentration about $5.1 \mathrm{mg} / \mathrm{m}^{3}$ and respirable dust concentration 1.3 , while the minimum rebound rate is about $5.8 \%$ at $0.3 \mathrm{Mpa}$ wind pressure because the relative large wind pressure contributes more to compacted concrete layer.

It can be obtained from practices $[21,45]$ that if the wind pressure is relatively small, the concrete stream in terms of flat parabolic motion with low kinetic energy resulted in the low velocity of some coarse aggregates, and these aggregates cannot reach the concrete layer. At the same time, in addition, it is difficult for the concrete sprayed on the surface with much concrete slurry and less aggregate to meet the strength requirements. However, when the wind pressure is relatively large, the spraying velocity of concrete materials is very fast with large impact force and kinetic energy, the material clusters are easily broken to produce dust under the action of a large shearing force from high wind pressure, and the dust produced is easily blew away in the roadway. The coarse aggregates with high velocity are easy to rebound, and the nozzleman is more exposed to rebounding particles. Moreover, no matter how much the wind pressure is, a suitable headgear should be worn in the vicinity of the nozzle operation, especially shotcreting the top of a roadway. Some safety equipment such as a protective clothing will help
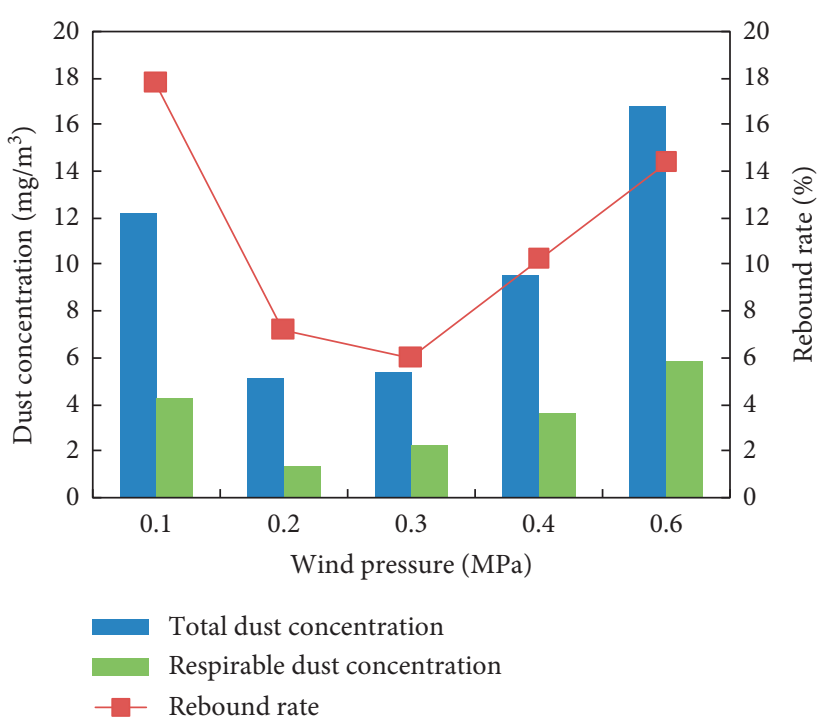

FIgURE 10: Relation between dust concentration, rebound ratio, and wind pressure (WA1).

prevent serious injury from dust and rebound. Hence, it is necessary to determine the optimal wind pressure that is about $0.2 \mathrm{MPa}$ under the condition of about $1 \mathrm{~m}$ spraying distance.

6.3. Spraying Angle. The spraying angle may influence the spraying efficiency containing dust concentration and rebound rate $[43,45]$. Hence, the shotcrete experiments with WA1 materials were conducted by changing various angles from $50^{\circ}$ to $90^{\circ}$ (the spray nozzle is perpendicular to the wall) at $1 \#$ point, with $1 \mathrm{~m}$ spraying distance and $0.2 \mathrm{MPa}$ wind pressure. The relation between dust concentration, rebound rate, and spraying angle are shown in Figure 11.

Figure 11 indicates that both of dust concentration and rebound rate declined with the angle from 50 to $90^{\circ}$. The angle between 80 and $90^{\circ}$ had less effect on rebound rate, $5 \%$ and $4.5 \%$, respectively. However, spraying angle had a significant impact on dust concentration, the minimum total dust concentration with the $90^{\circ}$ was $4.4 \mathrm{mg} / \mathrm{m}^{3}$, reduced by about $40 \%$ of that at $80^{\circ}$, as well as the respirable dust concentration. Therefore, in the process of wet-mix shotcrete, it needs to adjust the angle of the nozzle timely at the range of $80-90^{\circ}$ to ensure the best effect of wet-mix shotcrete. In addition, when shotcreting an interior corner or encasing reinforcing steel, the gun should be held at a slight angle from vertical to obtain good coating effect. But, the angle should not be less than $70^{\circ}$.

In summary, the relationship between the wind pressure, the spraying angle, the type of the accelerator, and the condition of the face sprayed, including the first and multiple shotcrete, should be coordinated and adjusted timely to reduce the dust concentration and rebound rate for better spraying efficiency in the work area.

\section{Conclusions}

This paper analyzed the mechanism of dust production in shotcreting process from the perspective of multidust 


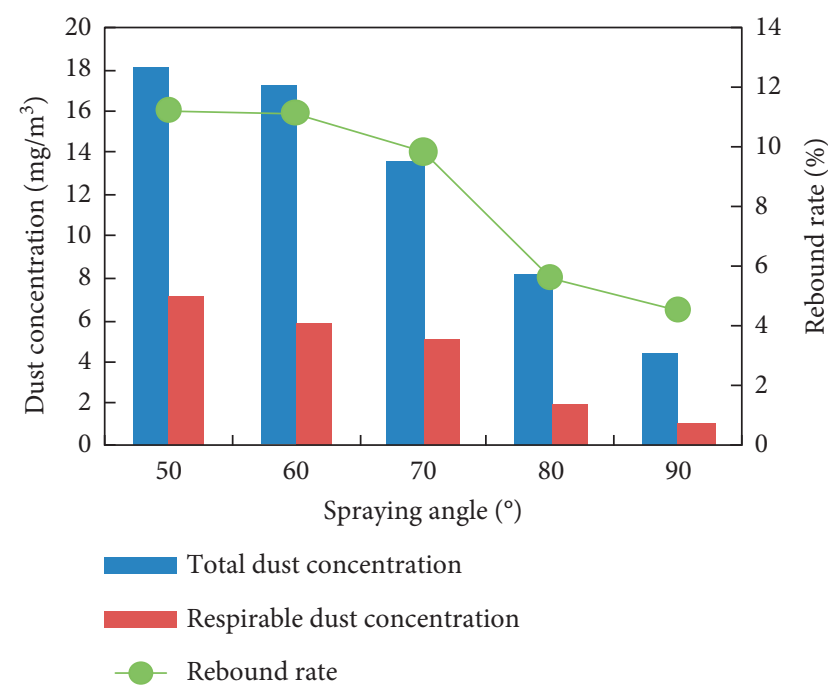

FIgURE 11: The influence of spraying angle on dust concentration and rebound rate (WA1).

sources, mainly including the dust produced in spraying process and the dust produced in the loading process. In the process of spraying, the dust is mainly generated by the diffusion effect and shear and collision of spraying airflow with high velocity. In the process of loading materials, the dust is mainly produced by the pulverization action caused by the shear of compressed air with the dropping of materials.

With the mechanism of dust production, the wetmix shotcrete equipment containing "plunger-type" wet spraying machine and wet mixing machine was developed for the small-section roadway or tunnel, whose width, respectively, was $0.98 \mathrm{~m}$ and $1.3 \mathrm{~m}$. And, the long-distance pumping concrete can be achieved with these machines for reducing the moving frequency of wet-mix shotcrete equipment.

Experiments of dust and rebound measurement were conducted in Tangkou roadway underground, and the results showed that when compared with dry spraying, the average dust concentration of wet-mix shotcrete in the whole working area reduced by more than $90 \%$. And, according to the distribution of dust in wet-mix shotcrete process, the dust safe zones of wet-mix shotcrete were divided into "dust warning area," "dust early warning area," and "clean area." Hence, it was suggested that the relevant equipment and workers should be placed in the "clean area" as far as possible.

Finally, the technology used for dust suppression in the process of wet-mix shotcrete was optimized. According to the comprehensive comparison, the dust concentration after the application of the accelerator was reduced by about 55\%. Both dust concentration and rebound rate declined and then increased with the increase in wind pressure, also declining with the angle from 50 to $90^{\circ}$. When wind pressure was $0.2 \mathrm{MPa}$ and spraying angle was $90^{\circ}$ under the condition of $1 \mathrm{~m}$ spraying distance, the efficiency of wet-mix shotcrete was optimal with the new wet-mix shotcrete equipment.

\section{Data Availability}

The data used to support the findings of this study are included within the article.

\section{Conflicts of Interest}

The authors declare that they have no conflicts of interest.

\section{Acknowledgments}

This study was funded by projects such as the National Key Research and Development Plan of the 13th Five-Year Period (grant no. 2017YFC0805203), Key Research and Development Plan of Shandong Province (grant no. 2018GSF116001), National Natural Science Foundation of China (grant no. 51604163), Applied Research Project Foundation of Qingdao Postdoctoral Researcher (grant no. 2015176), Student Innovation Fund of College of Mining and Safety Engineering in SDUST (grant no. KYKC17002), and Project of Shandong Province Higher Educational Science and Technology Program (grant no. J15LH03).

\section{References}

[1] G. Wang, M. Wu, R. Wang, and X. Xu, "Height of the mininginduced fractured zone above a coal face," Engineering Geology, vol. 216, pp. 140-152, 2017.

[2] G. Wang, W. Li, P. Wang, and S. Yang, "Deformation and gas flow characteristics of coal-like materials under triaxial stress conditions," International Journal of Rock Mechanics and Mining Sciences, vol. 91, pp. 72-80, 2017.

[3] Z. Liu, H. Yang, W. Wang, W. Cheng, and L. Xin, "Experimental study on the pore structure fractals and seepage characteristics of a coal sample around a borehole in coal seam water infusion," Transport in Porous Media, vol. 125, no. 2, pp. 289-309, 2018.

[4] X. Wang, Y. Zhang, B. Liu, P. Liang, and Y. Zhang, "Effectiveness and mechanism of carbamide/fly ash cenosphere with bilayer spherical shell structure as explosion suppressant of coal dust," Journal of Hazardous Materials, vol. 365, pp. 555-564, 2019.

[5] N. Guanhua, D. Kai, L. Shang, and S. Qian, "Gas desorption characteristics effected by the pulsating hydraulic fracturing in coal," Fuel, vol. 236, pp. 190-200, 2019.

[6] G. Ni, Z. Li, and H. Xie, "The mechanism and relief method of the coal seam water blocking effect (WBE) based on the surfactants," Powder Technology, vol. 323, pp. 60-68, 2018.

[7] B. Kong, E. Wang, and Z. Li, "The effect of high temperature environment on rock properties-an example of electromagnetic radiation characterization," Environmental Science and Pollution Research, vol. 2018, pp. 1-11, 2018.

[8] L. Xin, Z.-t. Wang, G. Wang, W. Nie, G. Zhou, and W.-m. Cheng, "Technological aspects for underground coal gasification in steeply inclined thin coal seams at Zhongliangshan coal mine in China," Fuel, vol. 191, pp. 486-494, 2017.

[9] J. Xie, L. Liu, J. Cao, X. Yan, and F. Zhang, "Mechanism and application of concrete-filled steel tubular support in deep and high stress roadway," Construction and Building Materials, vol. 186, pp. 233-246, 2018. 
[10] D. L. Zhang and Y. Z. Bi, "Application of wet concrete spraying technology in mine roadway," Advanced Materials Research, vol. 634-638, pp. 3294-3297, 2013.

[11] G. Zhou, W. Cheng, and S. Cao, "Development of a new type of alkali-free liquid accelerator for wet shotcrete in coal mine and its engineering application," Advances in Materials Science and Engineering, vol. 2015, Article ID 813052, 14 pages, 2015.

[12] W. Nie, X. Ma, W. Cheng, Y. Liu, L. Xin, and W. Wei, “A novel spraying/negative-pressure secondary dust suppression device used in fully mechanized mining face: a case study," Process Safety and Environmental Protection, vol. 103, pp. 126-135, 2016.

[13] L. D. G. Peng, "Situation and development direction of dust prevention and treatment for China coal mine," Metal Mine, no. S1, pp. 747-752, 2009.

[14] B. Bakke, B. Ulvestad, Y. Thomassen, T. Woldbaek, and D. G. Ellingsen, "Characterization of occupational exposure to air contaminants in modern tunnelling operations," Annals of Occupational Hygiene, vol. 58, no. 7, pp. 818-829, 2014.

[15] W. Cheng, X. Liu, G. Ruan, Y. Guo, and G. Wang, "The theory and technology of enclosure dust-laying model in speeded advance of coal road," Journal of China Coal Society Beijing, vol. 34, pp. 203-207, 2009.

[16] L. Chen and G. Liu, "Airflow-dust migration law and control technology under the simultaneous operations of shotcreting and drilling in roadways," Arabian Journal for Science and Engineering, pp. 1-9, 2018.

[17] G. Liu, W. Cheng, and L. Chen, "Investigating and optimizing the mix proportion of pumping wet-mix shotcrete with polypropylene fiber," Construction and Building Materials, vol. 150, pp. 14-23, 2017.

[18] G. Zhou, H. Qiu, Q. Zhang, M. Xu, J. Wang, and G. Wang, "Experimental investigation of coal dust wettability based on surface contact angle," Journal of Chemistry, vol. 2016, Article ID 9452303, 8 pages, 2016.

[19] G. Zhou, Q. Zhang, R. Bai, T. Fan, and G. Wang, "The diffusion behavior law of respirable dust at fully mechanized caving face in coal mine: CFD numerical simulation and engineering application," Process Safety and Environmental Protection, vol. 106, pp. 117-128, 2017.

[20] G. M. Liu and L. J. Chen, "Development of a new type of green switch air entraining agent for wet-mix shotcrete and its engineering application," Advances in Materials Science and Engineering, vol. 2016, Article ID 6981091, 9 pages, 2016.

[21] B. Bakke, P. Stewart, and W. Eduard, "Determinants of dust exposure in tunnel construction work," Applied Occupational and Environmental Hygiene, vol. 17, no. 11, pp. 783-796, 2002.

[22] Q. Liu, W. Nie, Y. Hua, H. Peng, and Z. Liu, "The effects of the installation position of a multi-radial swirling air-curtain generator on dust diffusion and pollution rules in a fullymechanized excavation face: a case study," Powder Technology, vol. 329, pp. 371-385, 2018.

[23] Q. Liu, W. Nie, Y. Hua, H. Peng, C. Liu, and C. Wei, "Research on tunnel ventilation systems: dust diffusion and pollution behaviour by air curtains based on CFD technology and field measurement," Building and Environment, vol. 147, pp. 444-460, 2019.

[24] S. Yang, W. Nie, S. Lv et al., "Effects of spraying pressure and installation angle of nozzles on atomization characteristics of external spraying system at a fully-mechanized mining face," Powder Technology, vol. 343, pp. 754-764, 2019.
[25] P. Cai, W. Nie, D. Chen, S. Yang, and Z. Liu, "Effect of air flowrate on pollutant dispersion pattern of coal dust particles at fully mechanized mining face based on numerical simulation," Fuel, vol. 239, pp. 623-635, 2019.

[26] W. Cheng, Z. Liu, H. Yang, and W. Wang, "Non-linear seepage characteristics and influential factors of water injection in gassy seams," Experimental Thermal and Fluid Science, vol. 91, pp. 41-53, 2018.

[27] Q. Zhang, G. Zhou, X. Qian, M. Yuan, Y. Sun, and D. Wang, "Diffuse pollution characteristics of respirable dust in fullymechanized mining face under various velocities based on CFD investigation," Journal of Cleaner Production, vol. 184, pp. 239-250, 2018.

[28] G. Zhou, Y. Ma, T. Fan, and G. Wang, "Preparation and characteristics of a multifunctional dust suppressant with agglomeration and wettability performance used in coal mine," Chemical Engineering Research and Design, vol. 132, pp. 729-742, 2018.

[29] M. T. Klare, "Clearing the air," National Interest, vol. 93, pp. 28-31, 2008.

[30] N. Wen, P. Huitian, L. Yanghao, M. Xiao, and W. Wenle, "Experimental research on the coupling and settlement of droplets and dust particles influenced by airflow," Journal of Shandong University of Science and Technology (Natural Science), vol. 6, pp. 30-36, 2016.

[31] K. Ono, "Health and safety in shotcreting," Tunnelling and Underground Space Technology, vol. 11, no. 4, pp. 391-409, 1996.

[32] J.-P. Won, B.-R. Choi, and J.-W. Lee, "Experimental and statistical analysis of the alkali-silica reaction of accelerating admixtures in shotcrete," Construction and Building Materials, vol. 30, pp. 330-339, 2012.

[33] X. Zhang, Y. Bai, H. Zhou, and H. Wang, "Study and application on dust comprehensive prevention and control technology in tunnel excavation by blasting," in Proceedings of 2nd International Symposium on Chemical Engineering and Material Properties, ISCEMP 2012, pp. 931-935, Trans Tech Publications, Taiyuan, Shanxi, China, June 2012.

[34] C. Shaojie, W. Hailong, W. Huaiyuan, G. Weijia, and L. Xiushan, "Strip coal pillar design based on estimated surface subsidence in Eastern China," Rock Mechanics and Rock Engineering, vol. 49, no. 9, pp. 3829-3838, 2016.

[35] M. P. Summers and J. P. Parmigiani, "A water soluble additive to suppress respirable dust from concrete-cutting chainsaws: a case study," Journal of Occupational and Environmental Hygiene, vol. 12, no. 4, pp. D29-D34, 2015.

[36] J.-G. Swanson and O. Langefeld, "Fundamental research in water spray systems for dust control," Mining Technology, vol. 124, no. 2, pp. 78-82, 2015.

[37] K. Ashrafi, M. Shafiepour-Motlagh, A. Aslemand, and S. Ghader, "Dust storm simulation over Iran using HYSPLIT," Journal of Environmental Health Science and Engineering, vol. 12, no. 1, p. 9, 2014.

[38] A. T. Hjelmfelt and L. F. Mockros, "Motion of discrete particles in a turbulent fluid," Applied Scientific Research, vol. 16, no. 1, pp. 149-161, 1966.

[39] W. S. Kessler, "Dust control in the chemical processing industries," Chemical Engineering, vol. 121, no. 7, p. 59, 2014.

[40] L. Chen, P. Li, G. Liu, W. Cheng, and Z. Liu, "Development of cement dust suppression technology during shotcrete in mine of China-a review," Journal of Loss Prevention in the Process Industries, vol. 55, pp. 232-242, 2018. 
[41] G. Zhou, Q. Zhang, W. Cheng, L. Chen, K. Feng, and W. Nie, "Numerical simulation on gunite dust of bolt-shotcrete operating area in coal mine and development of new wet spraying integral machine," Journal of Central South University of Technology, vol. 47, no. 2, pp. 606-614, 2016.

[42] L. R. Prudêncio, "Accelerating admixtures for shotcrete," Cement and Concrete Composites, vol. 20, no. 2-3, pp. 213219, 1998.

[43] S. A. Austin and P. J. Robins, Sprayed Concrete: Properties, Design and Application, Whittles Publishers, UK, 1995.

[44] G. Oettl, R. F. Stark, and G. Hofstetter, "A comparison of elastic-plastic soil models for 2D FE analyses of tunnelling," Computers and Geotechnics, vol. 23, no. 1, pp. 19-38, 1998.

[45] W. D. Brown, Standard Practice for Shotcrete Engineering and Design, US Army Corps of Engineers, Washington, DC, USA, 2005. 


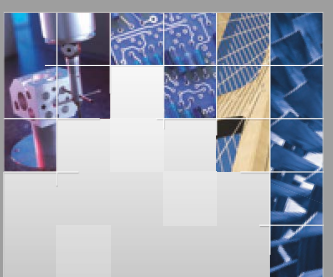

\section{Enfincering}
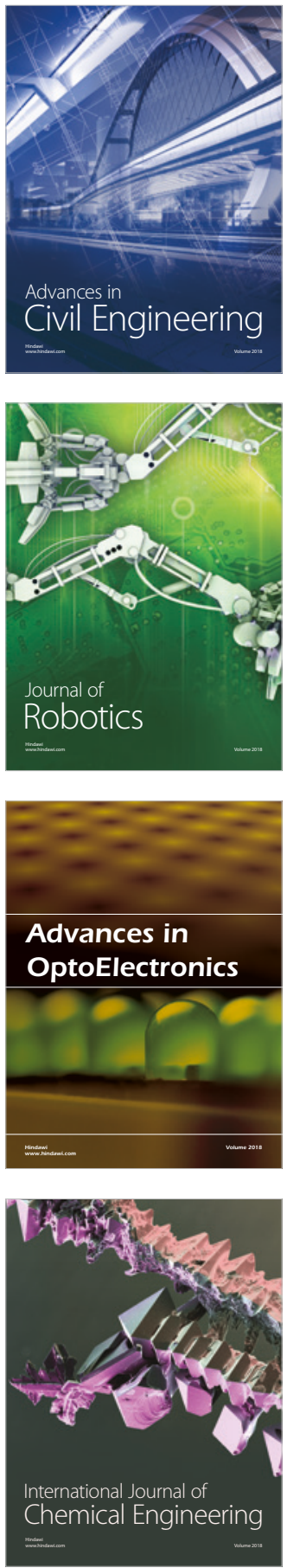

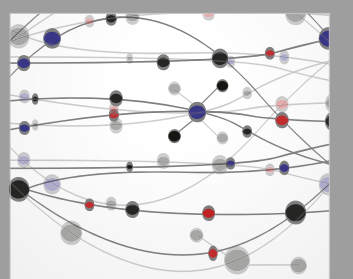

\section{Rotating \\ Machinery}

The Scientific World Journal

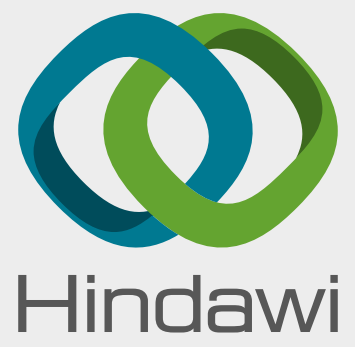

Submit your manuscripts at

www.hindawi.com
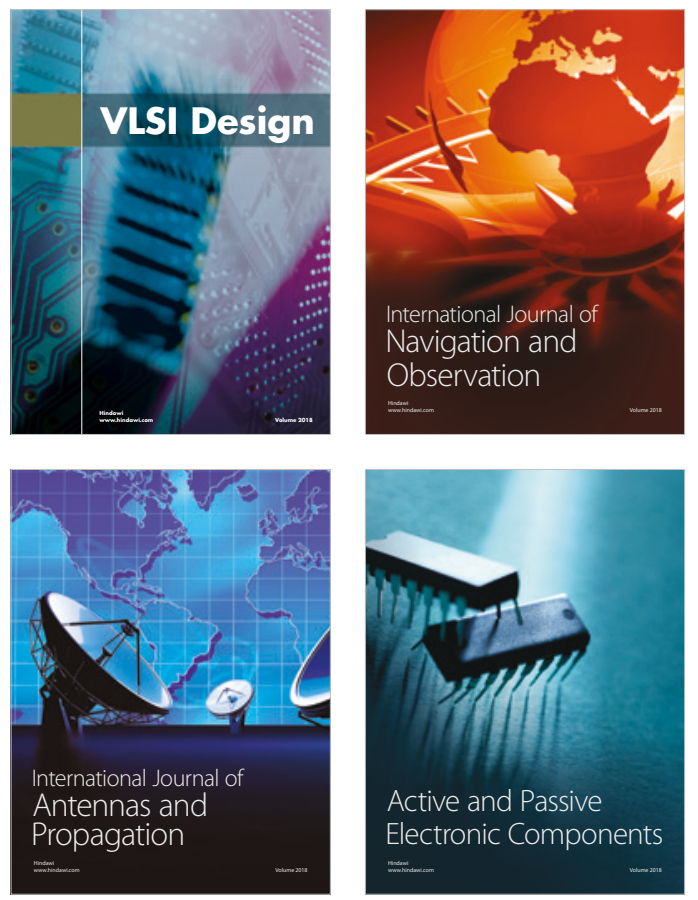
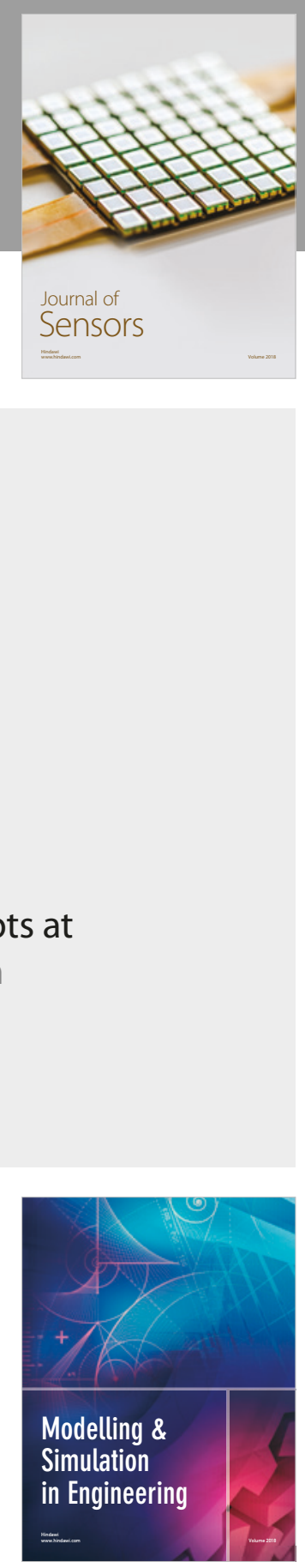

\section{Advances \\ Multimedia}
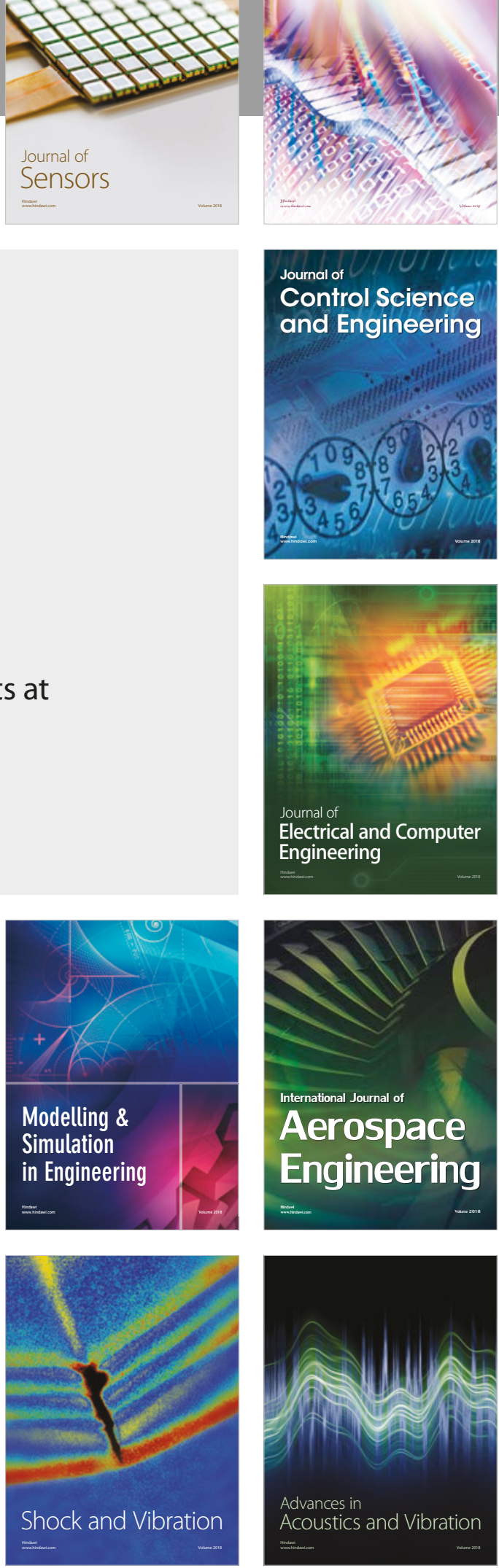